\title{
ESTUDO COMPARATIVO DO DESEMPENHO DE LEVEDURAS SACCHAROMYCES CEREVISIAE COMERCIAL E INDUSTRIAL E KLUYVEROMYCES MARXIANUS TERMOTOLERANTE
}

\author{
B. M. TOBAL ${ }^{1}$, N. S. de VARGAS ${ }^{2}$, M. L. C. G. ARAÚJO ${ }^{3}$, A. J. G. CRUZ ${ }^{1,2}$, R. G. \\ SILVA $^{1}$ \\ ${ }^{1}$ Universidade Federal de São Carlos, Departamento de Engenharia Química \\ ${ }^{2}$ Universidade Federal de São Carlos, Programa de Pós-Graduação em Engenharia \\ ${ }^{3}$ Universidade Estadual Paulista Julio de Mesquita Filho, \\ Departamento de Bioquímica e Tecnologia Química, Instituto de Química. \\ E-mail para contato: brunatobal@gmail.com
}

\begin{abstract}
RESUMO - A produção de etanol no Brasil é realizada por via fermentativa empregando a levedura Saccharomyces cerevisiae em temperaturas na faixa de 30 a $34^{\circ} \mathrm{C}$. Um dos problemas enfrentados pelas usinas, principalmente em regiões de clima quente, está relacionado com o controle da temperatura durante a fermentação, uma vez que o processo é exotérmico. Assim, este trabalho teve como objetivo avaliar o desempenho de uma levedura termotolerante do gênero Kluyveromyces marxianus em experimentos realizados a $40{ }^{\circ} \mathrm{C}$. Os resultados obtidos foram comparados com experimentos realizados com cepas comercial e industrial da levedura $S$. cerevisiae em experimentos realizados a $34^{\circ} \mathrm{C}$.
\end{abstract}

\section{INTRODUÇÃO}

O Brasil é o maior produtor mundial de etanol a partir da cana-de-açúcar, também chamado de etanol de primeira geração $(\mathrm{E} 1 \mathrm{G})$. O processo mais empregado industrialmente para a produção do etanol é a fermentação alcóolica utilizando a levedura Saccharomyces cerevisae. As fermentações industriais duram de 6 a 12 horas, a uma temperatura entre 32 e $35^{\circ} \mathrm{C}$, com um rendimento médio de etanol de 90 a $92 \%$ em relação a conversão teórica. Em países tropicais, há um grande gasto de energia com o resfriamento das dornas para manter a temperatura de cultivo em níveis aceitáveis de forma a não diminuir a viabilidade celular, o que resultaria em queda na produção de etanol.

Denominam-se leveduras termotolerantes aquelas capazes de manter o seu metabolismo a temperaturas iguais ou acima de $40{ }^{\circ} \mathrm{C}$ (Banat et al., 1998). A produtividade do processo fermentativo está atrelada a atividade das leveduras e dentre os fatores que podem influenciar o metabolismo das células, destaca-se a temperatura. Normalmente há um controle desta variável, pois o processo ocorre na faixa de temperatura ótima de $30-35{ }^{\circ} \mathrm{C}$ e as reações envolvidas na fermentação são exotérmicas (Vasconcelos, 2015). Contudo, em locais de clima quente manter a temperatura ótima de fermentação pode se tornar caro ou inviável. Neste contexto surgiu a necessidade de se utilizar leveduras que pudessem manter suas atividades celulares em temperaturas mais altas (Hacking et al., 1984), evitando assim possíveis paradas na produção devido ao superaquecimento dos reatores (Banat et al., 1998). A levedura 
Kluyveromyces marxianus é conhecida principalmente devido à sua capacidade de manter atividade metabólica em temperaturas elevadas $\left(37\right.$ a $\left.55^{\circ} \mathrm{C}\right)$.

O objetivo deste trabalho foi avaliar o desempenho fermentativo de uma linhagem da levedura termotolerante Kluyveromyces marxianus, isolada do processo industrial, a $40{ }^{\circ} \mathrm{C}$ com o de leveduras Saccharomyces cerevisiae (comercial e industrial) a $34^{\circ} \mathrm{C}$.

\section{MATERIAIS E MÉTODOS}

\subsection{Leveduras}

Nos experimentos realizados empregaram-se as leveduras Kluyveromyces marxianus (isolada de uma Usina do interior do Estado de São Paulo e gentilmente cedida pelo Prof. Dr. Anderson Ferreira - DGE/UFSCar) e as leveduras Saccharomyces cerevisiae comercial (AB Brasil, Pederneiras, SP) e industrial (Y-904, AB Brasil Pederneiras, SP) na forma liofilizada. Para as fermentações usando a levedura termotolerante foi preparado inóculo transferindo-se um criotubo contendo a levedura para um frasco de Erlenmeyer de $1 \mathrm{~L}$ contendo $100 \mathrm{~mL}$ de meio estéril, que continha (em g/L): sacarose, $110 ; \mathrm{KH}_{2} \mathrm{PO}_{4}, 5,6 ; \mathrm{MgSO}_{4} .7 \mathrm{H}_{2} \mathrm{O}, 1,4$; extrato de levedura, 6,8; e ureia, 5,32. O pH foi ajustado para 4,5 e a incubação ocorreu em shaker a $250 \mathrm{rpm}$ por 10 horas a $40^{\circ} \mathrm{C}$. Nos ensaios empregando as leveduras $S$. cerevisiae na forma liofilizada pesou-se a massa necessária para iniciar cada fermentação.

\subsection{Fermentações}

As fermentações foram realizadas em duplicata em frascos de Erlenmeyer de $250 \mathrm{~mL}$, contendo $100 \mathrm{~mL}$ de meio, o qual continha (em g/L): sacarose, 180; $\mathrm{KH}_{2} \mathrm{PO}_{4}, 5,6$; $\mathrm{MgSO}_{4} \cdot 7 \mathrm{H}_{2} \mathrm{O}$, 1,4; extrato de levedura, 6,8 e ureia, 5,32 (Sonego, 2016). As fermentações foram realizadas em câmara incubadora rotativa (shaker) com agitação de $200 \mathrm{rpm}$ por 10 horas nas temperaturas de $34^{\circ} \mathrm{C}$ para as leveduras comercial e industrial e $40^{\circ} \mathrm{C}$ para a termotolerante. $\mathrm{O}$ pH foi ajustado para 4,5. Foi usada concentração celular inicial de $13 \mathrm{~g} / \mathrm{L}$ para as leveduras industrial e comercial e $12 \mathrm{~g} / \mathrm{L}$ para a termotolerante.

O ensaio em biorreator usando a levedura termotolerante foi realizado no modo batelada convencional em um biorreator pneumático tipo coluna de bolhas, encamisado de $2 \mathrm{~L}$ volume útil, em $\mathrm{pH} 4,5$ por $9 \mathrm{~h}$ a $40^{\circ} \mathrm{C}$. A agitação se deu por recirculação de meio, utilizando bomba peristáltica (modelo $323 \mathrm{Dz}$ Watson Marlow). Acoplou-se um condensador $\left({ }^{\circ}{ }^{\circ} \mathrm{C}\right)$ ao biorreator de forma a minimizar perdas de etanol por evaporação.

\subsection{Análises}

A concentração celular foi determinada a partir de análise termogravimétrica da biomassa seca após centrifugação da amostra a $10.000 \mathrm{rpm}$ por 10 minutos a $4^{\circ} \mathrm{C}$. O precipitado foi lavado 2 vezes com água destilada para retirada de todas as impurezas. A secagem do precipitado foi feita em estufa a $80^{\circ} \mathrm{C}$ por $24 \mathrm{~h}$. Após esse período, pesou-se a massa de células secas para a determinação da concentração celular.

As concentrações de açúcares redutores totais (ART) e etanol foram determinadas empregando HPLC (Waters), equipado com detector de índice de refração. 
Determinação dos parâmetros cinéticos das fermentações: os coeficientes de rendimento de células (X) e etanol (E) em relação ao substrato (S) foram calculados segundo as equações 1 e 2 , respectivamente.

$$
\begin{gathered}
Y_{X / S}=\frac{C_{X}-C_{X_{0}}}{C_{S_{0}}-C_{S}} \\
Y_{E / S}=\frac{C_{E}-C_{E_{0}}}{C_{S_{0}}-C_{S}}
\end{gathered}
$$

Em que, $C_{R}$ e $C_{X_{0}}$ são as concentrações celulares, $C_{E}$ e $C_{E_{0}}$ são as concentrações de etanol e $C_{S}$ e $C_{S_{\mathrm{s}}}$ são as concentrações de substrato nos tempos final e inicial, respectivamente.

As produtividades volumétrica e específica do etanol foram calculadas a partir das equações 3 e 4 , respectivamente.

$$
\begin{aligned}
& P_{v}=\frac{C_{E}}{l_{f}} \\
& P_{v y p}=\frac{P v}{C_{x}}
\end{aligned}
$$

Em que, $\mathrm{Pv}$ é a produtividade volumétrica do etanol (g/L.h); $C_{E}$ é a concentração de etanol e $C_{x}$ é a concentração celular $(\mathrm{g} / \mathrm{L})$ no final da fermentação $(\mathrm{g} / \mathrm{L})$ e $\mathrm{t}_{\mathrm{f}}$ é o tempo de duração da fermentação (h).

$\mathrm{O}$ valor da velocidade máxima específica de crescimento das células $\left(\mathrm{h}^{-1}\right)$ foi calculado a partir da equação 5 na região de crescimento exponencial.

$$
\ln \frac{C x}{C x_{0}}=\mu_{m a x} \cdot\left(t-t_{0}\right)
$$

Em que, t é o tempo final referente à fase exponencial e $t_{0}$, seu tempo inicial.

\section{RESULTADOS E DISCUSSÃO}

As fermentações com as leveduras industrial e comercial foram realizadas a $34^{\circ} \mathrm{C}$, temperatura usualmente utilizada nas indústrias para a produção de etanol. Estes resultados foram comparados com a fermentação da levedura termotolerante à $40^{\circ} \mathrm{C}$ e são apresentados na Figura 1, que apresenta os gráficos das concentrações de açúcares redutores totais, células e etanol.

Pode se observar pela Figura 1 que a levedura comercial consumiu o açúcar mais rápido, no entanto, percebe-se que nas três fermentações o açúcar foi consumido totalmente na $9^{a}$ hora. A levedura industrial foi a que mais produziu células em sua fermentação, sendo este ponto negativo, pois o objetivo é a produção de etanol no processo. 
Figura 1 - Concentrações de açúcares redutores totais, de células e de etanol das leveduras industrial $(\square)$ e comercial $(\bullet)$ à $34^{\circ} \mathrm{C}$ e da termotolerante $(\Delta)$ à $40^{\circ} \mathrm{C}$.

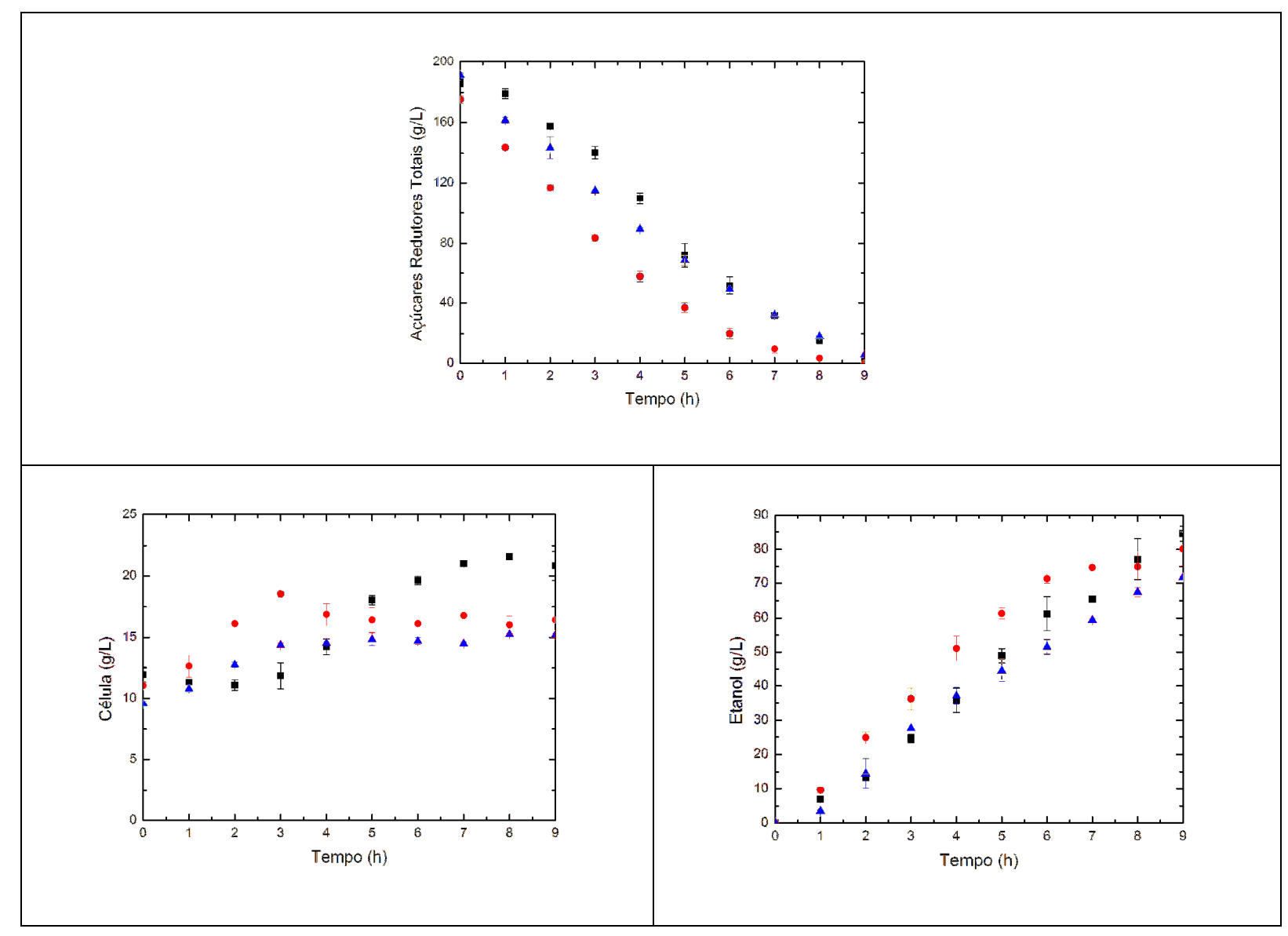

A levedura comercial e termotolerante apresentaram a mesma produção de células na última hora da fermentação, porém com comportamentos diferentes. A comercial foi a que produziu mais rápido o etanol até a sétima hora e a industrial foi a que produziu maior concentração de etanol. Observa-se que a levedura termotolerante teve um comportamento mais lento e produziu uma menor concentração de produto.

Para comparação foram realizados ensaios com as três linhagens de leveduras à $40^{\circ} \mathrm{C}$. Os resultados das fermentações são apresentados na Figura 2 para concentrações de açúcares redutores totais, células e etanol, respectivamente.

Observa-se pela Figura 2 que a levedura comercial e termotolerante apresentaram perfil semelhante de consumo de açúcares, sendo que ao final das nove horas de cultivo o substrato de ambas já tinha sido praticamente todo consumido. Já a levedura industrial, com o aumento da temperatura, consumiu mais lentamente os açúcares. Com relação à formação do produto, a industrial foi a que produziu menor quantidade de etanol, o que já era esperado, já que o consumo de açúcar não foi total. 
Figura 2 - Concentrações de açúcares redutores totais, de células e de etanol das leveduras industrial (•), comercial (•) e da termotolerante $(\Delta)$ à $40^{\circ} \mathrm{C}$

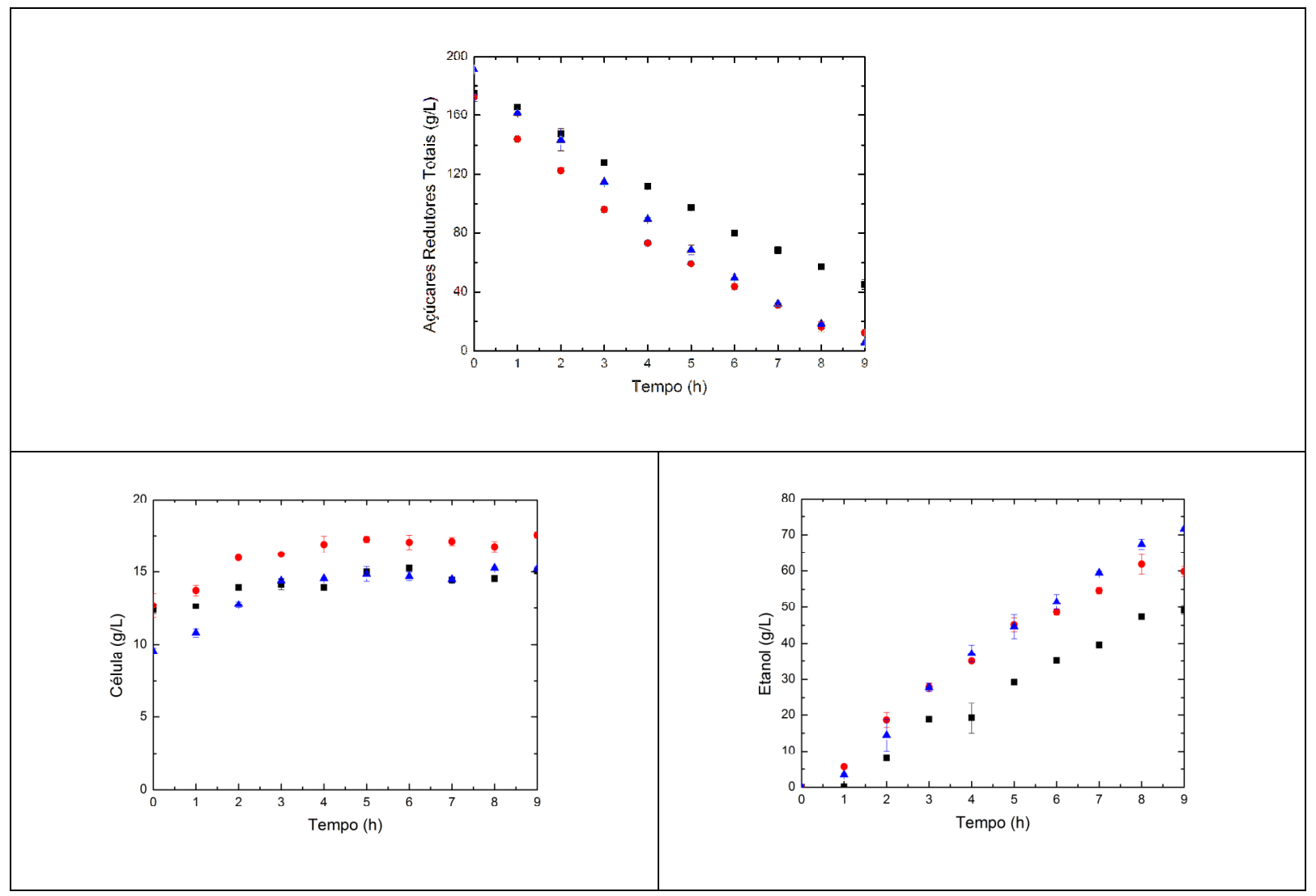

A partir da análise dos resultados obtidos é possível dizer que a linhagem industrial não conseguiu manter o desempenho fermentativo em temperaturas acima de sua temperatura ótima, o que foi comprovado tanto pelo consumo de substrato, que não foi total, quanto pela produção de etanol. O mesmo é possível aferir a respeito do desempenho da linhagem comercial, pois no processo a $34^{\circ} \mathrm{C}$ os açúcares acabaram entre a $8^{\mathrm{a}}$ e $9^{\mathrm{a}}$ hora de fermentação sendo que a $40{ }^{\circ} \mathrm{C}$ o consumo não foi completo e ficou constante nas duas últimas horas do processo. Além disso, a produção de etanol por esta linhagem foi menor a $40^{\circ} \mathrm{C}$.

Foram analisados alguns parâmetros das fermentações, como os coeficientes de rendimento de células-substrato, de etanol-substrato, produtividade específica e volumétrica de etanol e a velocidade específica de crescimento celular. Estes resultados estão indicados na Tabela 1.

Comparando o comportamento da linhagem industrial e comercial a $34^{\circ} \mathrm{C}$ e a $40^{\circ} \mathrm{C}$ observa-se que houve uma diminuição em todos os parâmetros. Para a levedura comercial, exceto o coeficiente de rendimento células-substrato que se manteve constante. Logo, as duas linhagens de leveduras sentiram o efeito do aumento de temperatura do processo. 
Tabela 1 - Valores dos coeficientes de rendimento de células-substrato, etanol-substrato, produtividade volumétrica e específica de etanol e da velocidade específica máxima de crescimento celular das linhagens industrial, comercial e termotolerante

\begin{tabular}{|c|c|c|c|c|c|}
\hline & $\begin{array}{c}\text { 349C - } \\
\text { Industrial }\end{array}$ & $\begin{array}{c}\text { 349-C - } \\
\text { Comercial }\end{array}$ & $\begin{array}{c}40{ }^{\circ} \mathrm{C}- \\
\text { Industrial }\end{array}$ & $\begin{array}{l}\text { 40ㄷ - } \\
\text { Comercial }\end{array}$ & $\begin{array}{c}409 \mathrm{C}- \\
\text { Termotolerante }\end{array}$ \\
\hline$Y_{x / s}(g x / g s)$ & 0,048 & 0,030 & 0,020 & 0,030 & 0,030 \\
\hline $\mathrm{Y}_{\mathrm{e} / \mathrm{s}}$ (ge/gs) & 0,457 & 0,457 & 0,378 & 0,374 & 0,386 \\
\hline$P_{\text {esp }}$ (ge/gx.h) & 0,45 & 0,59 & 0,36 & 0,38 & 0,52 \\
\hline$P_{v}(g / L . h)$ & 9,39 & 9,37 & 5,46 & 6,65 & 7,96 \\
\hline$\mu_{\text {máx }}\left(h^{-1}\right)$ & 0,147 & 0,1754 & 0,0237 & 0,0735 & 0,140 \\
\hline
\end{tabular}

Comparando todas as leveduras cultivadas a $40^{\circ} \mathrm{C}$, observa-se que os parâmetros da termotolerante são maiores ou iguais aos da industrial e comercial. Desse modo, avaliando todos os coeficientes na Tabela 1, pode-se dizer a linhagem termotolerante é promissora em relação à produção de etanol em altas temperaturas, já que mostrou bons valores de rendimento e produtividade.

Por fim, realizou-se uma fermentação com a levedura termotolerante em biorreator à $40^{\circ} \mathrm{C}$ para analisar o efeito do aumento de escala na produção de etanol. Os resultados desta foram comparados com os resultados dos frascos agitados e são mostrados na Figura 3.

Figura 3 - Concentrações de açúcares redutores totais (•), de células (•) e de etanol (४) nos frascos agitados e concentrações de açúcares redutores totais $(\bullet)$, de células $(\bullet)$ e de etanol ( $\Delta)$ no biorreator

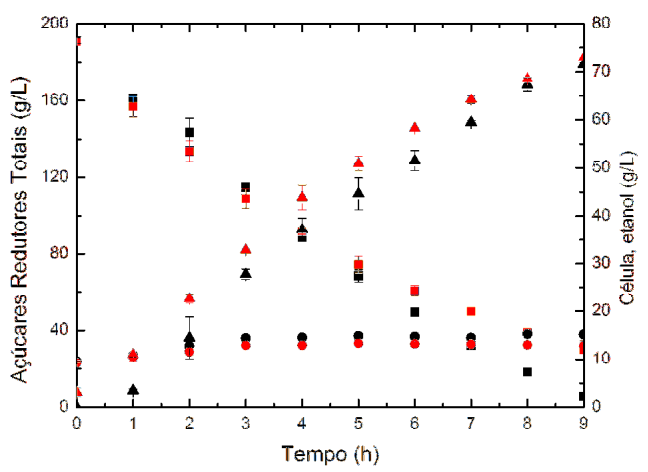

Comparando os resultados em biorreator e em frascos agitados observa-se que o consumo de açúcares foi similar até a $7^{\mathrm{a}}$ hora, quando houve uma diminuição na velocidade de consumo em biorreator. Desse modo, na última hora de fermentação, havia mais açúcares no biorreator. $\mathrm{O}$ crescimento de células nos dois modos foi similar em toda a fermentação. Além disso, a produção de etanol no biorreator ocorreu mais rápido do que nos frascos agitados e houve uma produção maior de etanol. 


\section{CONCLUSÃO}

Apesar de apresentar alguns parâmetros cinéticos fermentativos menores que as leveduras industrial e comercial cultivadas a $34^{\circ} \mathrm{C}$, pode-se dizer, que a levedura termotolerante Kluyveromyces marxianus é promissora na produção de etanol em temperaturas elevadas, uma vez que apresentou bons valores de rendimento e produtividade específica de etanol.

Agradecimentos: Os autores agradecem ao CNPQ, CAPES e FAPESP pelo apoio financeiro.

\section{REFERÊNCIAS}

BANAT, I. M. et al. Ethanol production at elevated temperatures and alcohol concentrations: Part I - Yeasts in general. World Journal of Microbiology \& Biotechnology, v. 14, n. 6, p. 809-821, Nov 1998.

HACKING, A. J.; TAYLOR, I. W. F.; HANAS, C. M. Selection of yeast able to produce ethanol from glucose at $40^{\circ} \mathrm{C}$. Applied Microbiology and Biotechnology, v. 19, n. 5, p. 361-363, Dez 1984.

SONEGO, J. L. S. Estudo Da Produção De Etanol De Sacarose Por Fermentação Extrativa Utilizando Arraste Com Dióxido De Carbono. 2016.

VASCONCELOS, J. N. Ethanol Fermentation. In: SANTOS F.; BORÉM A.; CALDAS C. Sugarcane. Agricultural production, Bioenergy and ethanol. Londres: Elsevier, 2015. p.311-329. 